\title{
High-Tech Service Platform Ecosystem Evolution: A Simulation Analysis using Lotka- Volterra Model
}

\author{
Jingdong YAN, Xiao YU*, Pincheng LIU, Quan ZHANG
}

\begin{abstract}
Technical service platform exerts a strong effect on supporting the innovation of the high-tech industry as a critical constituent of the modern service industry, and it can effectively enhance the development potential of technological innovation, but the degree of separation from technical service chain to high-tech industry chain is currently high. To explore how to improve the utilization efficiency of scientific and technological resources and facilitate the sustainable development of the high-tech industry by relying on technical service platform, a high-tech service platform was constructed by using Lotka-Volterra (L-V) model on the basis of ecosystem theory, the evolution path and stability conditions of high-tech service platform were analyzed followed by numerical simulation by Matlab computing. Results show that the development of hightech service platform follows the evolution path of "bilateral platform $\rightarrow$ core platform $\rightarrow$ platform ecosystem"; population evolution pattern in high-tech service platform ecosystem is decided by interdependence coefficient between populations; populations inside high-tech service platform ecosystem generate natural selection and synergistic effect and realize ecological balance among populations through evolution. Evolution of high-tech service platform system in this study provides a new theoretical framework for effective fusion and collaboration of science and technology service and industry, which is significant for elevating scientific and technological innovation level and improving technical service system construction.
\end{abstract}

Keywords: ecosystem evolution; high-tech industry; L-V model; technical service platform

\section{INTRODUCTION}

With the global scientific and technological development and the increasingly fierce science and technology competition, scientific and technological innovation is progressively exerting prominent influences on economic growth, structural upgrading, and competitiveness improvement. On the basis of high technology, the high-tech industry is characterized by strong driving power, association, permeability, and plays a significant role in promoting rapid and healthy social and economic development, thereby attracting extensive attention [1]. Various countries globally are driving and supporting the development of their high-tech industries through all countless means. The high-tech industry development in China had a late start. Although the central and local governments have always taken the development of high-tech industry as an important development direction in policy formulation, the high-tech industry has been presenting a rapid growth trend in aspects of enterprise quantity, $R \& D$ input, technology input, and so on. According to the 2017 China Statistical Yearbook of High-Tech Industry, the quantity of high-tech enterprises in 2016 reached 30,800 , doubling that in 2005 . The R\&D expenditure of large- and medium-sized high-tech enterprises was RMB 243.76 billion, equivalent to 6.72 times of that in 2005. China still has a long way to go to gain on innovative countries, such as America, Germany, and Japan in high-tech innovation ability and transformation efficiency of scientific and technological resources. For example, the patent transfer rate of colleges and universities in developed countries, such as America, reached $50 \%$ [2], but it was only $6 \%$ in China. The hightech industry is a knowledge and technology doubleintensive industry. China has realized considerable growth of R\&D input, but its technology content does not enjoy the corresponding remarkable elevation, in that the science and technology competitiveness has remained at a low international status, and the root cause lies in low technological innovation efficiency [3]. Therefore, how to realize more scientific and reasonable configuration of scientific and technological resources and improve innovation efficiency have become problems needing urgent solutions in high-tech industry development.

As a type of organization, which integrates scientific and technological resources and provides scientific and technological innovation activities with various technology services, technical service platforms can promote open sharing and efficient utilization of scientific and technological resources and provide high-level and professional science and technology services for enterprises and the whole society. In addition, it has attracted extensive attention from scholars. From the macro-perspective, scholars have mainly conducted mechanism studies regarding platform design principle, system architecture, service collaboration, and so on. From the micro-perspective, they have mainly explored the concrete strategies or measures from profit model, service chain, and so on. In addition, various countries have conducted numerous practices to enhance their scientific and technological innovation capabilities and support the development of the high-tech industry, e.g. American Federal Laboratory Technology Transfer Consortium and National Technology Information Centre established a scientific and technological resource database to provide information inquiry services for relevant industry organizations by integrating national scientific and technological resources [4]. Semiconductor Manufacturing Technology Consortium improved American semiconductor manufacturing by integrating business capital resources in the consortium and sharing development technology research and financial risks [5].

However, high-tech service platforms in China have enjoyed certain developments, e.g., Shanghai Bioengineering and Pharmaceutical Industry Platform and Shenzhen Energy Emission and New Energy Low-Carbon Public Technology Platform, and so on. However, the theoretical exploration of platform development lags behind and most are still centering on simple scientific and technological intermediary service mode with insufficient 
recognition of evolution path of technical service platforms, and a lack exists of the optimal long-term planning layout for positioning technical service platforms. The government-dominated single development pattern cannot be changed and platforms are short of development motivation, failing to realize their due roles in improving innovation efficiency. Under this background, on the basis of the concept of ecological development and orienting at demands, this study investigated the evolution path for high-tech service platform ecosystem and explored their sustainable development problems to improve the resource integration efficiency of high-tech service platforms and to solve the fused development issues between the high-tech industry and technical service platforms.

The remainder of this study is arranged as follows. Section 2 combs the existing literature relating to high-tech industry and technical service platforms and puts forward the research thought of using the Lotka-Volterra $(\mathrm{L}-\mathrm{V})$ model to analyze high-tech service platforms. Section 3 analyzes the high-tech service platform ecosystem structure and evolution process. Section 4 constructs a high-tech service platform L-V model, conducts stability and simulation analyses, and discusses the above analysis results. Section 5 finally presents the conclusions.

\section{LITERATURE REVIEW}

The enormous promoting effect of high-tech industry development on economic growth has become a consensus among scholars $[6,7]$. Therefore, how to facilitate the development of high-tech industry has become the main research content at home and abroad. By combing relevant literature, this study found that scholars have investigated how to promote the development of the high-tech industry mainly from four aspects, namely, financial support, industrial clustering, technological innovation, and governmental support. Woolley deemed that for the hightech industry, risk capital market was its best direct financing channel, and the construction of American risk capital market exerted important effects on the development of American high-tech industry [8]. Through an empirical analysis, Liu et al. unveiled that increasing scientific research input can improve the technological innovation performance of the high-tech industry to boost its development [9]. Ren et al. probed the influence of clustering of different industry types on technological innovation and found that the difference of cluster type would influence enterprise participation to influence enterprise cooperation in innovation [10]. Dmitriev et al. thought that high-tech industry clustering could accelerate the technological innovation of the high-tech industry and lower product cost [11]. By constructing a combing model, Amitrano et al. found that the higher the market competition level, the higher the enterprises' technological innovation level [12]. Li et al. thought that excess governmental invention would obstruct the improvement of total factor productivity of the high-tech industry [13].

With the deepening of high-tech industry studies, the high-tech industry fails to satisfy the requirements for innovation activities by only relying on its own restricted resources, but instead, it needs to actively acquire external innovation resources to solve resource bottlenecks in the innovation process [14]. As an important constituent of science and technology innovation system, technical service platform can gather knowledge, effectively integrate all kinds of science and technology innovation resources, and establish close relations between enterprises and factor market to provide great support for high-tech enterprises to improve innovation efficiency. In the relationship research between technical service platform and high-tech industry, Sangamuang believed that technical service platform was only occupied in simple professional information transfer service at the beginning and survived on innovation subjects [15]. Kakaomerlioglu et al. pointed out that without developed science and technology services as the support, for high-tech enterprises to own strong innovation ability and market competitiveness was difficult [16]. As believed by UribeEcheberra et al., technical service platforms played roles of innovation promoters, innovation platforms, and innovation sources in innovation activities [17]. Science and technology services are closely integrated with hightech innovation activities, technical service platforms facilitate innovation ability of the high-tech industry, and meanwhile, the improvement of innovation ability of the high-tech industry also boosts the development of technical service platforms [18].

Although many scholars have investigated technical service platforms, most of them have focused on concrete professional science and technology services, such as technology transfer [19-22], business incubation [23], intellectual property [24, 25], and science and technology financial platforms [26-28]. However, few full-chain technical service platforms established for specific industrial cluster mode exist. Studies regarding technical service platforms are carried out mainly from aspects of platform connotation [29-31], platform construction and operation [32, 33], platform service [34, 35], and so on. Centering platform and relying on networks, service and technical service platform associates several organizations and individuals according to certain rules with ecosystem features. Therefore, some scholars have investigated technical service platforms combining ecosystem theory. According to the individualized demands of innovation subjects in technological innovation ecosystem in different innovation phases, Qian modularized scientific and technological information services and explored into the path for providing accurate services. By analyzing constitutive factors of scientific and technological innovation ecosystem [36], Fan et al. thought that information, platform, and service were three important factors for sustainable development of Chinese scientific and technological periodicals [37]. Jacobides deemed that the collaboration degree between core platform and subjects was deepened with gradual improvement of the whole platform ecosystem in service pattern and function [38]. Wang et al. analyzed four typical scientific and technological financial platform cases from ecosystem architecture and operating mechanism, and discussed concrete measures for constructing regional scientific and technological financial platforms [28]. Inoue et al. deemed that multiple platform ecosystems, if collaborated, could effectively realize functional complementation and facilitate sustainable development of platform ecosystem [39]. 
$\mathrm{L}-\mathrm{V}$ model was only applied to studies relating to species competition in ecosystem in the early development phase, and then it was introduced into the economic field as a suitable model explaining the competition and cooperation relationship between enterprises. In the classic thesis Predator and Prey: A New Ecological Competition, Moore described the evolutionary phases of industrial ecosystem birth, expansion, predominance, and selfrenewal as well as cooperation and competition features in each phase [40]. Taking technical index as an important dimensionality, Pan et al. used L-V model to study the evolution of innovation ecosystem, thus providing a basis for the future scientific and technological development trend and decision formulation [41]. $\mathrm{Li}$ et al. investigated knowledge creation mechanism of industrial technology innovation network via L-V model [42]. Wei et al. used the $\mathrm{L}-\mathrm{V}$ model to analyze competitive and collaborative innovation evolutions between innovation subjects [43].

From the existing literature, the abovementioned studies have provided substantial reference for descendants' studies on technical service platforms, but the following problems still exist. First, studies on the collaborative innovation problem between technical service platform and high-tech industry remain limited, lacking fusion and failing to realize accurate orientation of science and technology services at high-tech industrial demands with low integration efficiency of scientific and technological resources. Based on studies regarding technical service platform ecosystem, most of the existing literature has concentrated on structural framework, service pattern, and business model, but research on evolutionary stability of the whole ecosystem and relevant simulation studies are insufficient.

Given this, under the background of development trend and demand of the high-tech industry, this study constructed a high-tech service platform ecosystem. This study used the L-V model to investigate the stability of system evolution to provide a theoretical basis for opening the "black box"-how high-tech service platforms can promote the development of the high-tech industry, enrich research results of high-tech service platforms, and further improve sustainable development ability of high-tech service platforms.

\section{METHODOLOGY \\ 3.1 System Structure}

The composition of a high-tech service platform ecosystem can be divided into four layers according to natural ecosystem elements, that is, individual, population, community, and ecosystem, and complex organic connection exists between ecological units at different layers. Similarly, members in high-tech service platform systems complete one another's advantages with resource sharing and collaborative evolution. Under coordination and integration of core platforms, other platforms with competitive and symbiotic relationships jointly form an ecosphere with abundant layers and complex relationships through circular flow of scientific and technological resources as shown in Tab. 1.

Table 1 Factor comparison between natural ecosystem and high-tech service platform ecosystem

\begin{tabular}{|c|l|l|}
\hline Definition & \multicolumn{1}{|c|}{ Natural ecosystem } & \multicolumn{1}{|c|}{ High-tech service platform ecosystem } \\
\hline Individual & $\begin{array}{l}\text { Organic individuals of organisms with growth, development, and } \\
\text { reproduction functions }\end{array}$ & $\begin{array}{l}\text { High-tech enterprises and science and technology service-oriented } \\
\text { enterprises constituting the high-tech service platform ecosystem }\end{array}$ \\
\hline Population & $\begin{array}{l}\text { Set of biological individuals with the same gene frequency, } \\
\text { morphologies, and physiological characteristics }\end{array}$ & $\begin{array}{l}\text { Enterprise set with similar abilities and characteristics on a high- } \\
\text { tech service platform }\end{array}$ \\
\hline Community & Set of different biological populations & $\begin{array}{l}\text { Constituted by all populations with different characteristics in a } \\
\text { high-tech service platform }\end{array}$ \\
\hline Ecosystem & $\begin{array}{l}\text { Organic body composed of different biological communities and } \\
\text { natural environment }\end{array}$ & $\begin{array}{l}\text { Organic unified whole composed of different high-tech service } \\
\text { platforms and external environment }\end{array}$ \\
\hline
\end{tabular}

Different types of high-tech enterprises such as advanced manufacturing companies, bio-pharmaceutical companies, etc. are the basic units in the high-tech service platform ecosystem, similar to the biological individuals in the natural ecosystem. They also belong to the subdivided industry belonging to the high-tech service platform formed by the industrial population. Different types of industrial groups formed some high-tech service communities. Finally, all high-tech enterprises in the hightech service platform and its radiation range constitute the entire high-tech service platform ecosystem.

\subsection{Evolution Path}

Moore was the first one who applied ecology to the management field [44]. He divided the development of business ecosystem into four phases. The first phase was foundation of business ecosystem. In the second phase, business ecosystem attracted new members to expand the platform boundary by providing relevant high value-added products and services. With the development of business ecosystem, ecological niches of population members would be re-divided in the third phase. The fourth phase was sustainable innovation phase of business ecosystem.

Just as evolution and development of a single organization, the growth of high-tech service platforms is also a process of continuously realizing value maximization with the evolution of their life cycle. According to analysis theory of business ecosystem, this study defined the evolution path of high-tech service platform ecosystem and it was divided into bilateral platform, core platform, and platform ecosystem phases as shown in Fig. 1.

\subsection{Modelling}

Jointly proposed by American ecologist Lotka and Italian mathematician Volterra, the L-V model is a theoretical model used to describe competitive relationships between species. Based on population dynamics Logistic model, this model extends the study objects from single species to interaction between multiple species and it lays the theoretical foundation for studying interpopulation competitive relationships. As ecology is introduced into the management field, L-V model has also 
been used to study relationships between enterprises and has achieved significant effect. Therefore, this study attempts to analyze the stability of interpopulation evolution in high-tech service platform ecosystem via L-V model.

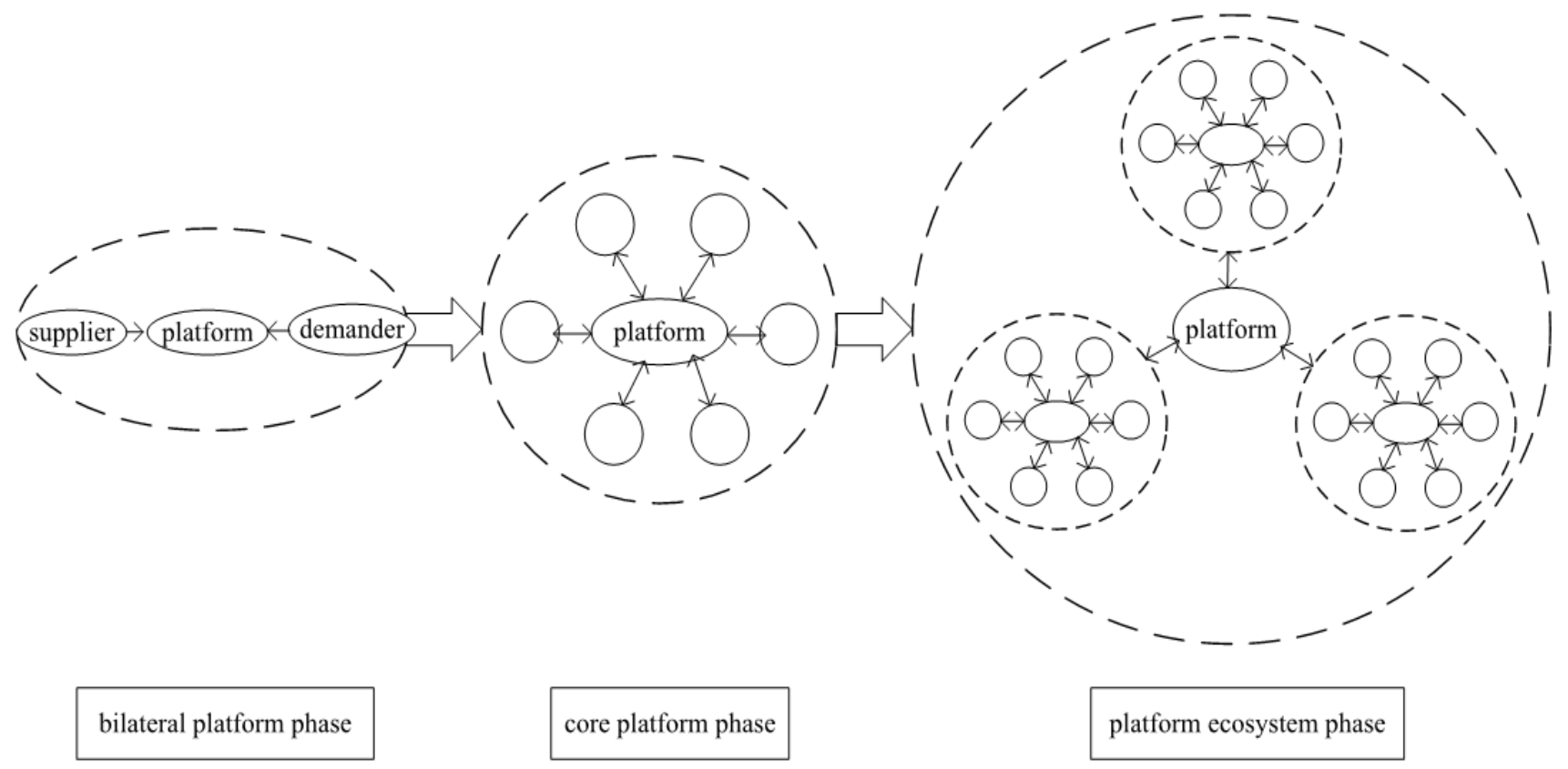

Figure 1 Evolution path of high-tech service platform ecosystem

As the interpopulation evolution model where population quantity in high-tech service platform ecosystem exceeds two is totally similar to the model where the population quantity is two. For the convenience of analysis, assume that the high-tech service platform ecosystem consists of two populations, and that population growth is restricted by environmental factors similar to the growth process of ecosystem in nature, and moreover, it needs to undergo the development process from childhood to adulthood.

Assume that the resources in the high-tech service platform ecosystem in operation and growth phase (phase $t$ ) are restricted, scales of two populations grow with time, the evolution scales of the two populations are set as $v_{1}(t)$ and $v_{2}(t)$, their growth rates are $r_{1}$ and $r_{2}$, respectively. $k_{1}$ and $k_{2}$ denote maximum scales of the two populations under given resources in the community. Hence, the evolutionary L-V model between the two populations in the high-tech service platform ecosystem is constructed as below:

$$
\left\{\begin{array}{l}
\frac{\mathrm{d} v_{1}}{\mathrm{~d} t}=v_{1} r_{1}\left(1-\frac{v_{1}}{k_{1}}-\frac{\alpha_{1} v_{2}}{k_{2}}\right) \\
\frac{\mathrm{d} v_{2}}{\mathrm{~d} t}=v_{2} r_{2}\left(1-\frac{v_{2}}{k_{2}}-\frac{\alpha_{2} v_{2}}{k_{1}}\right)
\end{array}\right.
$$

$\alpha_{1}$ and $\alpha_{2}$ are interdependence coefficients between two populations, namely, the influence of interpopulation relationship of the two populations on their evolutions. The value ranges of $\alpha_{1}$ and $\alpha_{2}$ decide interpopulation relationship between the two populations as seen in Tab. 2 .

Table 2 Value ranges of interdependency coefficients $\alpha_{1}, \alpha_{2}$, and corresponding interpopulation relationship

\begin{tabular}{|l|l|l|}
\hline Value range & Interpopulation relationship & Main features \\
\hline$\alpha_{1}=0, \alpha_{2}=0$ & Neutral relationship & Do not generate mutual effect and develop independently \\
\hline$\alpha_{1}>0, \alpha_{2}>0$ & Competitive relationship & Inhibit each other \\
\hline $\begin{array}{l}\alpha_{1}<0, \alpha_{2}=0 \text { or } \alpha_{1}=0, \alpha_{2}<0 \\
\alpha_{1}<0, \alpha_{2}=0 \text { or } \alpha_{1}=0, \alpha_{2}<0\end{array}$ & Commensalism relationship & One party in the population benefits whereas the other party does not \\
\hline $\begin{array}{l}\alpha_{1}>0, \alpha_{2}=0 \text { or } \alpha_{1}=0, \alpha_{2}>0 \\
\alpha_{1}>0, \alpha_{2}=0 \text { or } \alpha_{1}=0, \alpha_{2}>0\end{array}$ & Amensalism relationship & One party in the population suffers loss whereas the other party does not \\
\hline$\alpha_{1}<0, \alpha_{2}<0$ & Mutually beneficial relationship & Generate beneficial effect on each other \\
\hline $\begin{array}{l}\alpha_{1}<0, \alpha_{2}>0 \text { or } \alpha_{1}>0, \alpha_{2}<0 \\
\alpha_{1}<0, \alpha_{2}>0 \text { or } \alpha_{1}>0, \alpha_{2}<0\end{array}$ & Parasitic relationship & $\begin{array}{l}\text { One party in the population can survive and develop only by relying on the other } \\
\text { party }\end{array}$ \\
\hline
\end{tabular}

The evolution result of populations in the high-tech service platform ecosystem depends on values of interdependence coefficients $\alpha_{1}$ and $\alpha_{2}$. Therefore, to better explore the internal population evolution in high-tech service platform ecosystem, this study used the simulation software Matlab 2018b to conduct systematic stability analysis and simulation of collaborative evolution of two populations in high-tech service platform ecosystem.
Set upper limits of development scale of populations 1 and 2 as $k_{1}=1,000$ and $k_{2}=800$, respectively, their growth rates as $r_{1}=0.05$ and $r_{2}=0.02$, respectively, and number of iterations as 500. By adjusting the values of interdependence coefficients, the evolution trends under different relationships between populations are acquired accordingly. 


\section{RESUILT ANALYSIS AND DISCUSSION 4.1 Stability Analysis}

First, equilibrium point analysis of Eq. (1) is performed.

$\left\{\begin{array}{l}\frac{\mathrm{d} v_{1}}{\mathrm{~d} t}=v_{1} r_{1}\left(1-\frac{v_{1}}{k_{1}}-\frac{\alpha_{1} v_{2}}{k_{2}}\right)=0 \\ \frac{\mathrm{d} v_{2}}{\mathrm{~d} t}=v_{2} r_{2}\left(1-\frac{v_{2}}{k_{2}}-\frac{\alpha_{2} v_{2}}{k_{1}}\right)=0\end{array}\right.$

Four local equilibrium points of interpopulation evolution in high-tech service platform ecosystem can be obtained as $\mathrm{A}(0,0), \quad \mathrm{B}\left(k_{1}, \quad 0\right), \quad \mathrm{C}\left(0, k_{2}\right)$ and $\mathrm{D}\left(\frac{k_{1}\left(1-\alpha_{1}\right)}{1-\alpha_{1} \alpha_{2}}, \frac{k_{2}\left(1-\alpha_{2}\right)}{1-\alpha_{1} \alpha_{2}}\right)$.

According to the interpopulation evolution process in high-tech service platform ecosystem as described by differential equations, the stability of its equilibrium points can be acquired through local stability analysis of the Jacobian matrix. Therefore, partial derivatives of $v_{1}$ and $v_{2}$ are solved for the differential equations to obtain the
Jacobian matrix of interpopulation evolution in the hightech service platform ecosystem:

$$
\boldsymbol{J}=\left|\begin{array}{cc}
r_{1}-\frac{2 r_{1} v_{1}}{k_{1}}-\frac{r_{1} \alpha_{1} v_{2}}{k_{2}} & -\frac{r_{1} \alpha_{1} v_{1}}{k_{2}} \\
-\frac{r_{2} \alpha_{2} v_{2}}{k_{1}} & r_{2}-\frac{2 r_{2} v_{2}}{k_{2}}-\frac{r_{2} \alpha_{2} v_{1}}{k_{1}}
\end{array}\right|
$$

Therefore, the determinants of this Jacobian matrix is

$$
\begin{aligned}
& \operatorname{det}(\boldsymbol{J})=\left(r_{1}-\frac{2 r_{1} v_{1}}{k_{1}}-\frac{r_{1} \alpha_{1} v_{2}}{k_{2}}\right)\left(r_{2}-\frac{2 r_{2} v_{2}}{k_{2}}-\frac{r_{2} \alpha_{2} v_{1}}{k_{1}}\right)- \\
& -\left(\frac{r_{2} \alpha_{2} v_{2}}{k_{1}}\right)\left(\frac{r_{1} \alpha_{1} v_{1}}{k_{2}}\right) \text { and } \\
& \operatorname{tr}(\boldsymbol{J})=\left(r_{1}-\frac{2 r_{1} v_{1}}{k_{1}}-\frac{r_{1} \alpha_{1} v_{2}}{k_{2}}\right)+\left(r_{2}-\frac{2 r_{2} v_{2}}{k_{2}}-\frac{r_{2} \alpha_{2} v_{1}}{k_{1}}\right) .
\end{aligned}
$$

The method of using Jacobian matrix to judge whether equilibrium point is under local stable state is: when system equilibrium satisfies $\operatorname{det}(\boldsymbol{J})>0$ and $\operatorname{tr}(\boldsymbol{J})<0$, equilibrium point is then under local asymptotic stability state, so the equilibrium conditions for interpopulation evolution in the high-tech service platform ecosystem are $\operatorname{det}(\boldsymbol{J})>0$ and $\operatorname{tr}(\boldsymbol{J})<0$. The concrete analysis results are shown in Tab. 3 .

Table 3 Equilibrium point for interpopulation evolution in high-tech service platform ecosystem and stability analysis

\begin{tabular}{|c|c|c|c|}
\hline Equilibrium point & $\operatorname{det}(\boldsymbol{J})$ & $-\operatorname{tr}(\boldsymbol{J})$ & $-\left(r_{1}+r_{2}\right)$ \\
\hline $\mathrm{A}(0,0)$ & $r_{1} r_{2}$ & $r_{1}-r_{2}\left(1-\alpha_{2}\right)$ \\
\hline $\mathrm{B}\left(k_{1}, 0\right)$ & $-r_{1} r_{2}\left(1-\alpha_{2}\right)$ & $r_{2}-r_{1}\left(1-\alpha_{1}\right)$ & $\alpha_{1}<1, \alpha_{2}>1$ \\
\hline $\mathrm{C}\left(0, \mathrm{k}_{2}\right)$ & $-r_{1} r_{2}\left(1-\alpha_{1}\right)$ & $\alpha_{1}>1, \alpha_{2}<1$ \\
\hline $\mathrm{D}\left(\frac{k_{1}\left(1-\alpha_{1}\right)}{1-\alpha_{1} \alpha_{2}}, \frac{k_{2}\left(1-\alpha_{2}\right)}{1-\alpha_{1} \alpha_{2}}\right)$ & $\frac{r_{1} r_{2}\left(1-\alpha_{1}\right)\left(1-\alpha_{2}\right)}{1-\alpha_{1} \alpha_{2}}$ & $\frac{r_{1}\left(1-\alpha_{1}\right)+r_{2}\left(1-\alpha_{2}\right)}{1-\alpha_{1} \alpha_{2}}$ \\
\hline
\end{tabular}

After equilibrium points and stability conditions are obtained, the evolution process between two populations in the high-tech service platform ecosystem can be described through phase trajectory analysis method to investigate the evolution trend and some characteristics, and the following is set:

$$
\begin{aligned}
& g_{1}\left(v_{1}, v_{2}\right)=1-\frac{v_{1}(t)}{k_{1}}-\alpha_{1} \frac{v_{2}(t)}{k_{1}} \\
& g_{2}\left(v_{1}, v_{2}\right)=1-\frac{v_{1}(t)}{k_{1}}-\alpha_{1} \frac{v_{2}(t)}{k_{1}}
\end{aligned}
$$

where the positions of $g_{1}\left(v_{1}, v_{2}\right)=0$ and $g_{2}\left(v_{1}, v_{2}\right)=0$ on the phase plane are decided by value ranges of $\alpha_{1}$ and $\alpha_{2}$. For different interdependence coefficients, the evolution trajectory will tend to be different equilibrium points.

When $\alpha_{1}<1$ and $\alpha_{2}>1$, then the equilibrium point $\mathrm{B}\left(k_{1}, 0\right)$ is the stable point. Two straight lines $g_{1}\left(v_{1}, v_{2}\right)=0$ and $g_{2}\left(v_{1}, v_{2}\right)=0$ divide the phase plane into three regions $S_{1}, S_{2}$, and $S_{3}$, specifically as shown in Fig. 2a.

$$
\begin{aligned}
& S_{1}=\frac{\mathrm{d} v_{1}(t)}{\mathrm{d} t}>0, \frac{\mathrm{d} v_{2}}{\mathrm{~d} t}>0 \\
& S_{2}=\frac{\mathrm{d} v_{1}(t)}{\mathrm{d} r}>0, \frac{\mathrm{d} v_{2}}{\mathrm{~d} t}<0
\end{aligned}
$$

$$
S_{3}=\frac{\mathrm{d} v_{1}(t)}{\mathrm{d} t}<0, \frac{\mathrm{d} v_{2}}{\mathrm{~d} t}<0
$$

Fig. 2a shows that $S_{1}$ region is located at the lower overlapping part of oblique lines $g_{1}=0$ and $g_{2}=0$, where scale growth rates of Populations 1 and 2 are greater than zero. $S_{2}$ region is below oblique line $g_{1}=1$ and above oblique line $g_{2}=0$, where the scale growth rate of Population 1 is greater than zero but that of Population 2 is smaller than zero. $S_{3}$ region is located at the upper overlapping part of oblique lines $g_{1}=0$ and $g_{2}=0$, where the scale growth rates of Populations 1 and 2 are smaller than zero.

If the initial phase point is in $S_{1}$ region, it can be found according to Eq. (6) that growth rates of Population 1 and 2 are greater than zero, and the phase point will move toward the upper right with time, and then enter $S_{2}$ region. If the initial phase point is located in $S_{2}$ region, it can be found through Eq. (7) that the scale growth rate of Population 1 is greater than zero whereas that of Population 2 is smaller than zero and the phase point will move toward the lower right with time, and finally tend to equilibrium stability point B. If the initial phase point is in $S_{3}$ region, it can be found through Eq. (8) that the scale growth rates of Populations 1 and 2 are smaller than zero, and phase point will move toward the lower left with time, and finally tend to equilibrium stability point $\mathrm{B}$.

Through the above analysis, when $\alpha_{1}<1$ and $\alpha_{2}>1$, equilibrium point for evolution of the two populations is 
$\mathrm{B}\left(k_{1}, 0\right)$, namely, no matter which region the initial phase point is located, the scale of Population 1 will continuously grow whereas Population 2 will disappear, finally realizing stable development at equilibrium stability point $\mathrm{B}$.

Similarly, it can be proven that when $\alpha_{1}>1$ and $\alpha_{2}<1$, $\mathrm{C}\left(0, k_{2}\right)$ is the equilibrium point for evolution, namely, the scale of Population 2 will continuously grow whereas Population 1 will disappear. Under $\alpha_{1}<1$ and $\alpha_{2}<1$,
$\mathrm{D}\left(\frac{k_{1}\left(1-\alpha_{1}\right)}{1-\alpha_{1} \alpha_{2}}, \frac{k_{2}\left(1-\alpha_{2}\right)}{1-\alpha_{1} \alpha_{2}}\right)$ is the equilibrium point for evolution, and the two populations can realize stable coexistence in the ecosystem. When $\alpha_{1}>1$ and $\alpha_{2}>1$, no global stability point exists. Moreover, the phase trajectory analysis process under the three circumstances is similar to the analysis process of equilibrium point $\mathrm{B}$. Therefore, the final evolution results are shown in Figs. 2 b, 2 c, and $2 d$.

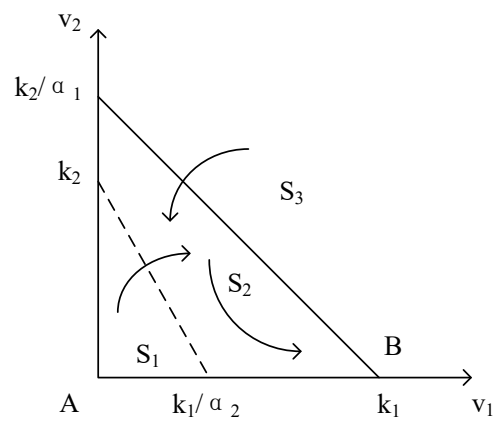

(a) When $\alpha_{1}<1$ and $\alpha_{2}>1$, point $B$ is stable

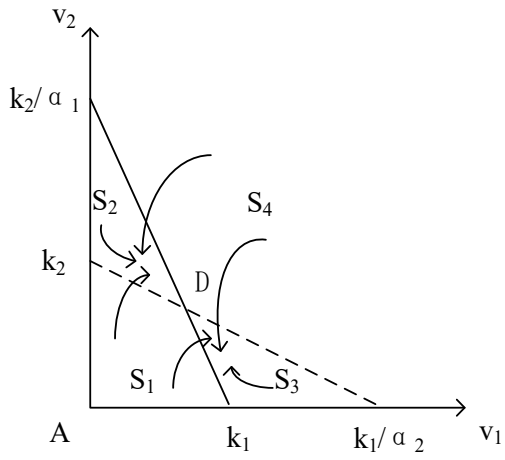

(c) When $\alpha_{1}<1$ and $\alpha_{2}<1$, point $D$ is stable Figure 2 Phase diagram of interpopulation evolution in high-tech service platform
Based on the above analysis, only when $\alpha_{1}<1$ and $\alpha_{2}$ $<1$ will a stable coexistence state exist in the high-tech service platform ecosystem. Therefore, interpopulation relationships and setting of simulation values in Section 3.3 were combined to conduct a simulation of possible neutral, competitive, commensalism, amensalism relationship, mutually beneficial, and parasitic relationships under $\alpha_{1}<$ 1 and $\alpha_{2}<1$ conditions.

(1) Neutral relationship

Under neutral relationship, no mutual effect will be generated between two populations in ecosystem, so $\alpha_{1}=0$ and $\alpha_{2}=0$ are set. The simulation results are shown in Fig. 3 and it can be found that the development speeds of two populations do not influence each other in the high-tech service platform ecosystem, both of which are decided by their inherent growth rates, and moreover, after a certain time, their scales reach upper limits.

(2) Competitive relationship

Under competitive relationship, two populations in the ecosystem can inhibit each other, so $\alpha_{1}=0.3$ and $\alpha_{2}=0.3$ are set. The simulation results are shown in Fig. 4 and it can be found that the development speeds of two populations in the high-tech service platform ecosystem will be lower than their inherent growth rates. Furthermore, their scales do not reach upper limits due to the influence of competition.

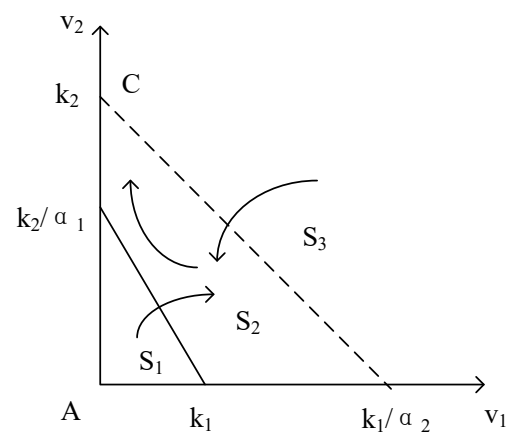

(b) When $\alpha_{1}>1$ and $\alpha_{2}<1$, point $\mathrm{C}$ is stable

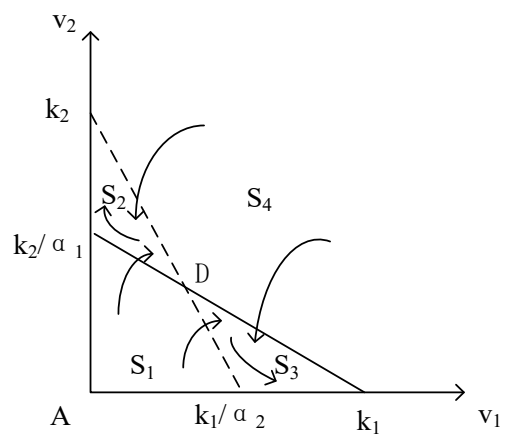

(d) When $\alpha_{1}>1$ and $\alpha_{2}>1$, there is no stable point

(3) Commensalism relationship

Under commensalism relationship, one between two populations in the ecosystem will benefit whereas the other party will not, so $\alpha_{1}=0$ and $\alpha_{2}=-0.3$ are set. The simulation results are shown in Fig. 5. It can be found that one party (Population 1 with zero interdependence coefficients) in the high-tech service platform ecosystem is not influenced whereas the development scale of the other party (Population 2 with negative interdependence coefficient) breaks through the original upper limit as it is benefited.

(4) Amensalism relationship

Under amensalism relationship, one between two populations in ecosystem will suffer loss whereas the other one will not, so $\alpha_{1}=0.3$ and $\alpha_{2}=0$ are set. The simulation results are presented in Fig. 6, and that one party (Population 2 with zero interdependence coefficient) is not influenced and under normal development whereas the upper limit of development scale of the other one (Population 1 with positive interdependence coefficient) is lowered somehow due to loss.

(5) Mutually beneficial relationship

Under mutually beneficial relationship, two populations in ecosystem promote each other's development, so $\alpha_{1}=-0.3$ and $\alpha_{2}=-0.3$ are set. The simulation results are shown in Fig. 7. It can be found that 
under mutually beneficial relationship, symbiotic effect is generated between two populations. When the evolution reaches stable state, the development scales of both populations break through their original upper limits.

(6) Parasitic relationship

Under parasitic relationship, interdependence coefficient of one between two populations in the ecosystem is greater than zero whereas that of the other one is smaller than zero, so $\alpha_{1}=0.3$ and $\alpha_{2}=-0.3$ are set. The simulation results are displayed in Fig. 8, from which it can be observed that the upper limit of development scale of parasitic Population 1 (interdependence coefficient is positive) in the high-tech service platform ecosystem is lowered to a certain degree as it is consumed by the other party, but the upper limit of development scale of Population 2 (interdependence coefficient is positive) is enlarged as it is benefited.

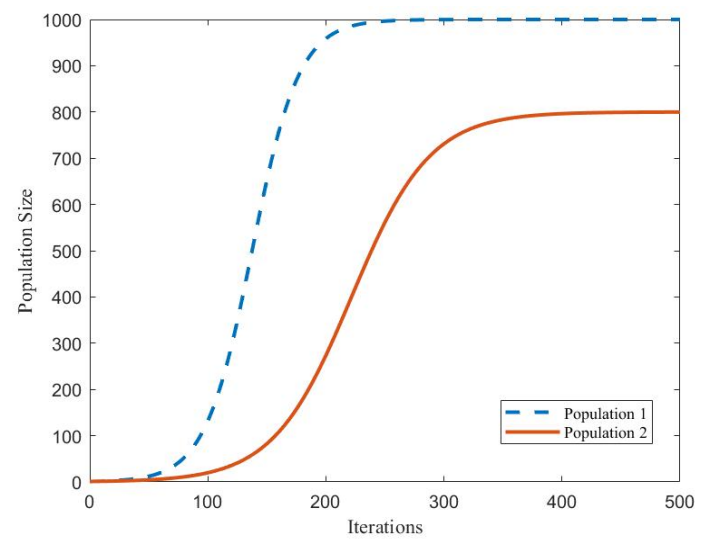

Figure 3 Interpopulation evolution patterns under neutral relationship

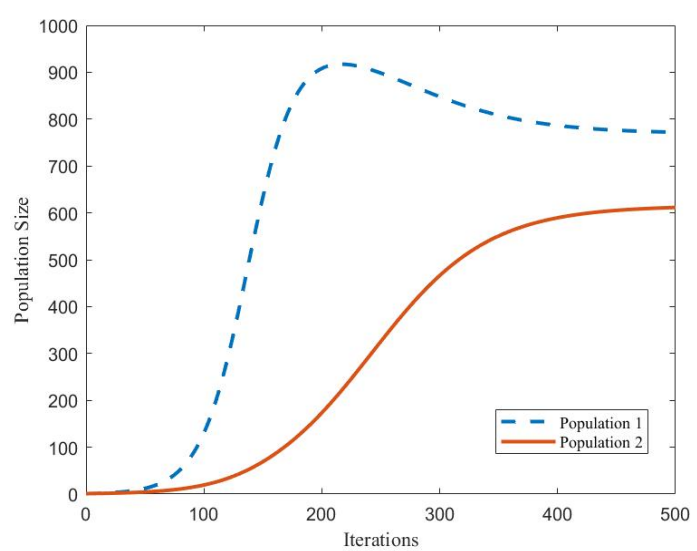

Figure 4 Interpopulation evolution patterns under competitive relationship

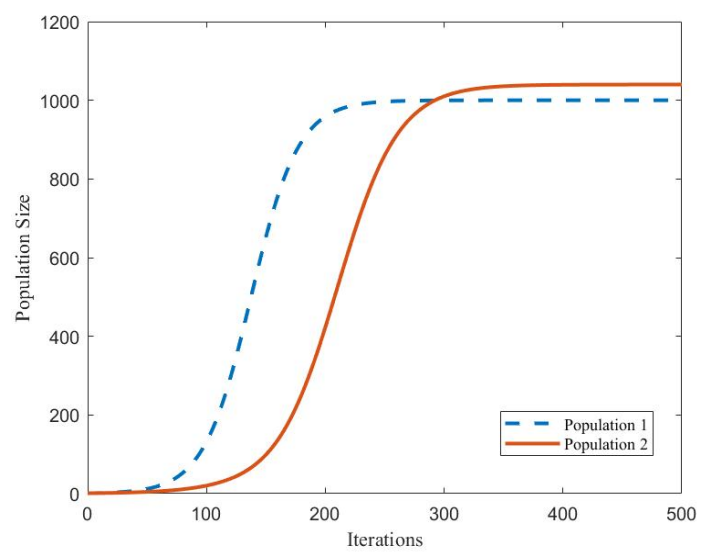

Figure 5 Interpopulation evolution patterns under commensalism relationship

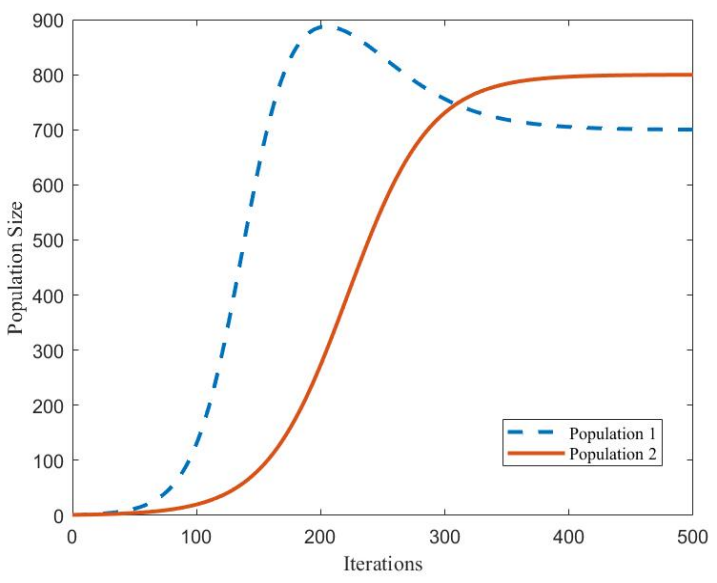

Figure 6 Interpopulation evolution patterns under amensalism relationship

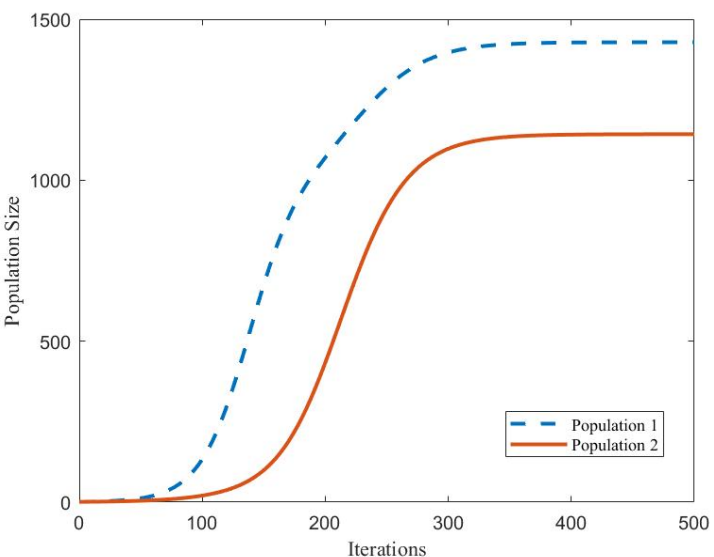

Figure 7 Interpopulation evolution patterns under mutually beneficial relationship

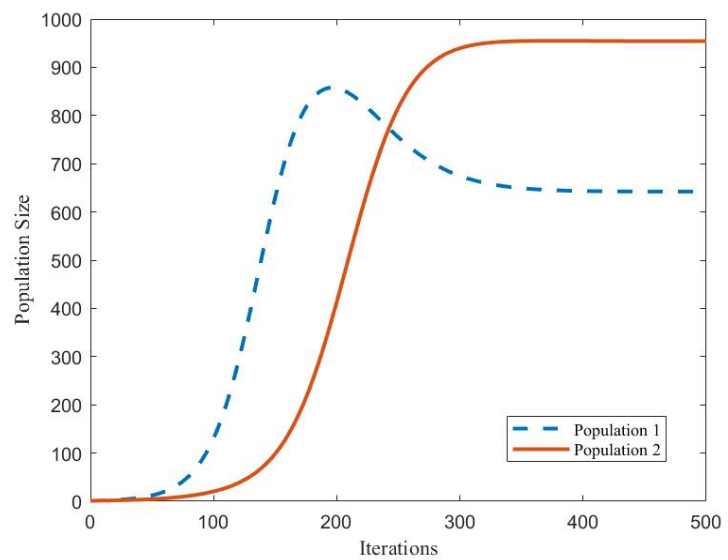

Figure 8 Interpopulation evolution patterns under parasitic pattern

\subsection{Discussion}

The above analysis indicates that the evolution result of high-tech service platform ecosystem depends on interdependence coefficients between populations in the platform, and different interpopulation relationships result in different evolution results, mainly manifested by the following features and laws:

(1) According to the results in Fig. 3, when the interpopulation interdependence coefficient is 0 , the population evolution process in high-tech service platform ecosystem is influenced by their environmental capacity and their own growth speed; they develop independently and have no mutual relationship. Fan et al. [45] and Nestor 
et al. [46] empirically studied the development efficiencies of the high-tech and science and technology service industries, but they ignored their mutual relationship. This mutually independent coexistence pattern in practice is not a normal existence and it does not conform to the sustainable development goal of high-tech service platform ecosystem.

(2) Based on the results in Fig. 4, when interpopulation interdependence coefficients are both greater than 0 , the interpopulation competition for resources in the high-tech service platform ecosystem is fierce and they inhibit each other's development. The party with greater interdependence coefficient will tend to decay or perish as other populations occupy resources while the other party can survive and develop. Under this circumstance, due to special restriction of population survival resources and influence of their mutual competition, the sum of overall development scales of populations in the high-tech service platform ecosystem will be smaller than the sum of maximum development scales they can originally reach.

(3) As shown in Figs. 5 and 6, when the interdependence coefficient of one party is 0 whereas that of the other party is not 0 , their relationship belongs to commensalism or amensalism patterns. Namely, symbiosis is unilateral, it is only beneficial for one party, and this "good to none but worse to oneself" or "good to others but bad to oneself" pattern is not suitable to exist for a long time.

(4) The results in Fig. 7 show that when the interdependence coefficients are both negative, the population evolution in the high-tech service platform ecosystem forms a mutually beneficial relationship, generates reciprocal symbiosis, and enhances development potentials. The existing studies have basically ascertained the interdependent relationship between high-tech and service industries, which are connected through innovation activities. The high-tech industry generates demands for the service industry while the service industry relies upon market and technology provided by the manufacturing industry $[47,48]$, but there lacks deep mechanism and trend studies regarding their collaborative innovation. This study reveals the evolution mechanism of high-tech service platform ecosystem and further expounds the path for hightech and service industries to realize benign interactive development. Given the cooperative promoting effect between populations, the sum of the overall development scales of populations in the high-tech service platform ecosystem will be greater than the sum of maximum development scales that they can reach by relying on their own growth, so it is an ideal symbiosis pattern.

(5) As shown in Fig. 8, when one interdependence coefficient is positive whereas the other is negative, the resources of one party will be transferred to the other party, so this party will benefit whereas the other party will suffer loss. This asynchronous evolution is of high instability and it goes against value creation.

Through the above discussion results, the key factor for healthy evolution of high-tech service platform ecosystem lies in the formation of mutually beneficial relationship between populations. By constructing a hightech service platform ecosystem, the evolution path of this platform is investigated from a systematic level in this study, the coordinating ability of core platform to handle the relationship with population set is taken as an important influence factor of value creation, and then integration efficiency of innovation resources is effectively improved. In the meantime, it is obtained through the analysis of evolution trend of the high-tech service platform ecosystem that competition and cooperation between populations drive system evolution, so only when two restriction factors interest driving and ecological equilibrium in the high-tech service platform ecosystem are well coordinated can we extend space of ecological niches and realize symbiotic evolution.

Therefore, to improve the overall collaborative service ability of the high-tech service platform ecosystem, on the one hand, the importance should be attached to labor division between populations, namely, population symbiosis should be realized through cooperation. On the other hand, the development environment should be optimized to construct benign competitive order between populations. The sustainable development of the high-tech service platform ecosystem can be realized by coordinating the relationship between population benefits and overall ecological equilibrium.

\section{CONCLUSION}

By establishing a collaborative evolution model between populations in the high-tech service platform ecosystem, a simulation analysis was carried out after the equilibrium points and stability conditions for the symbiotic evolution model were given, followed by an indepth discussion about the evolution process of the hightech service platform ecosystem. The conclusions can be drawn as follows:

(1) The high-tech service platform ecosystem follows the evolution path of "bilateral platform $\rightarrow$ core platform $\rightarrow$ platform ecosystem". The platform ecosystem phase is an advanced phase of the development of high-tech service platform, which improves the utilization efficiency of scientific and technological resources.

(2) During the internal population evolution process of the high-tech service platform ecosystem, competition and cooperation between populations are internal driving forces for their evolution, and interdependence coefficient is a critical factor influencing system evolution.

(3) The essence of evolution of the high-tech service platform ecosystem is a complex system of interaction between populations, and to maintain its healthy and sustainable development cannot be separated from symbiotic evolution between populations under their mutually beneficial relationship.

The limitation of this study mainly lies in that only the evolution between populations was analyzed. However, the evolutionary development between communities is also important as a constituent of the high-tech service platform ecosystem, and this will also be our further explore direction so that the study on high-tech service platform ecosystem would become more comprehensive.

\section{Acknowledgements}

This study was supported by National Key R\&D Program of China (Grant no. 2018YFB140430405). 


\section{REFERENCES}

[1] Toe, S. (1998). Network positions and propensities to collaborate: An investigation of strategic alliance formation in a high-technology industry. Administrative Science Quarterly, 43(3), 668-698. https://doi.org/10.2307/2393679

[2] Wu, Y., Welch, E. W., \& Huang, W. L. (2014). Commercialization of university inventions: Individual and institutional factors affecting licensing of university patents. Technovation, 36-37, 12-25. https://doi.org/10.1016/j.technovation.2014.09.004

[3] Zhu, Y. W., \& Xu, K. N. (2006). The empirical research on R\&D efficiency of Chinese high-tech industries. China Industrial Economy, 5(11), 38-45. https://doi.org/10.19581/j.cnki.ciejournal.2006.11.005

[4] Mathew, S., Ibrahim, S., \& Archbold, S. (2018). Corporate governance and firm risk. Corporate Governance: The International Journal of Business in Society, 18(1), 52-67. https://doi.org/10.1108/CG-02-2017-0024

[5] Grindley, P. \& Silverman, D. C. M. A. (1994). SEMATECH and collaborative research: Lessons in the design of hightechnology consortia. Journal of Policy Analysis \& Management, 13(4), 723-758. https://doi.org/10.2307/3325495

[6] Aldieri, L. \& Vinci, C. (2017). Innovation effects on employment in high-tech and low-tech industries: Evidence from large international firms within the Triad. Eurasian Business Review, (8), 229-243. https://doi.org/10.1007/s40821-017-0081-9

[7] Jang, S. S., Ko, H., Chung, Y., \& Woo, C. (2019). CSR, social ties and firm performance. Corporate Governance: The International Journal of Business in Society, 19(6), 1310-1323. https://doi.org/10.1108/CG-02-2019-0068

[8] Woolley, J. (2017). Origins and Outcomes: The roles of spinoff founders and intellectual property in high technology venture outcomes. Academy of Management Disvoveries, 1(3), 64-90. https://doi.org/10.5465/amd.2014.0138

[9] Liu, G. X., Ye, J., \& Argyres, C. (2020). Modeling and simulation of the knowledge growth process among new energy technology firms in the distributed innovation network. DYNA, 95(1), 54-60. https://doi.org/10.6036/9427

[10] Ren, H. \& Ye, M. (2018). Study on the spatial agglomeration division of Shanghai innovation function. Science and Technology Management Research, 10(16), 63-73. https://doi.org/10.3969/j.issn.1000-7695.2018.16.010

[11] Dmitriev, O. N. \& Novikov, S. V. (2019). Verification of feasibility studies at high-technology enterprises. Russian Engineering Research, 39(9), 780-781. https://doi.org/10.3103/S1068798X19090053

[12] Amitrano, C. C., Tregua, M., Spena, T. R., \& Bifulco, F. (2018). On technology in innovation systems and innovation-ecosystem perspectives: A cross-linking analysis. Sustainability, 10(10), 3744. https://doi.org/10.3390/su10103744

[13] Li, S. S. \& Zou, T. (2017). Government intervention, capital market distortion and total factor productivity: An empirical research on high-tech industry. Journal of Dongbei University of Finance and Economics, (2), 24-32. https://doi.org/ 10.3969/j.issn.1008-4096.2017.02.004

[14] Collins, C. J. \& Smith, K. G. (2006). Knowledge exchange and combination: The role of human resource practices in the performance of high-technology firms. Academy of Management Journal, 49(3), 544-560.

[15] Sangamuang, S. (2019). A graph-based algorithm for interpersonal ties clustering in signed networks. Tehnički Glasnik, 13(4), 275-279. https://doi.org/10.31803/tg-20191104192845

[16] Kakaomerlioglu, D. C. \& Carlsson, B. (1999). Manufacturing in decline? A matter of definition. Economics of Innovation and New Technology, 8(3), 175-196. https://doi.org/10.1080/10438599900000008
[17] Uribe-Echeberra, R., Igartua-Lopez, J. I., \& Lizarralde, R. (2020). Open innovation in research and technology organizations: an exploration of the phenomenon. DYNA, 95(1), 74-80. http://doi.org/10.6036/9166

[18] Hatane, S. E., Supangat, S., Tarigan, J., \& Jie, F. (2019). Does internal corporate governance mechanism control firm risk? Evidence from Indonesia's three high-risk sectors. Corporate Governance: The International Journal of Business in Society, 19(6), 1362-1376. https://doi.org/10.1108/CG-02-2019-0071

[19] Ma, Y. \& Rauf, A. (2019). Indigenous innovation, foreign technology transfer and the export performance of China's manufacturing industries. The Singapore Economic Review, 7(1), 1-22. https://doi.org/10.1142/S0217590819400034

[20] Battagliaa, D., Landonia, P., \& Rizzitellib, F. (2017). Organizational structures for external growth of university technology transfer offices: An explorative analysis. Technological Forecasting \& Social Change, 123, 45-56. https://doi.org/10.1016/j.techfore.2017.06.017

[21] Xu, K., Liu, H. B., \& Xiao, B. (2019). New development paradigm of technology transfer service organization: From the perspective of boundary organization. Studies in Science of Science, 37(7), 1231-1237. https://doi.org/10.16192/j.cnki.1003-2053.2019.07.009

[22] He, X. J., Ma, S., \& Wu, Y. Y. (2019). Research on the supply and demand matching of online technology trading platform based on multi-level feature Fusiono: Taking the data of Beijing-Tianjin-Hebei region as an example. Journal of Intelligence, 38(6), 174-181. https://doi.org/10.3969/j.issn.1002-1965.2019.06.026

[23] Li, X., Wang, Y., Fu, L., \& Xu, M. (2009). The university library: incubation center of research innovation literacy. Electronic Library, 27(4), 588-600. https://doi.org/10.1108/02640470910979552

[24] Li, L. C. \& Wei, S. S. (2015). The research on policy correlation of intellectual property intermediary Services System of Independent Innovation. Science and Technology Management Research, 35(18), 27-31. https://doi.org/10.3969/j.issn.1000-7695.2015.18.006

[25] Xu, K., Li, N., \& Bao, X. Z. (2019). Third-party intermediary platform participating in intellectual property pledge financing cooperation mechanism. Science and Technology Management Research, 39(5), 122-129. https://doi.org/10.3969/j.issn.1000-7695.2019.05.019

[26] Wang, X. F., Yu, M., \& Cheng, Y. (2018). The train of thought of construction science and technology financial platform for Beijing-Tianjin-Hebei. Economy and Management, 32(3), 17-21. https://doi.org/10.3969/j.issn.1003-3890.2018.03.003

[27] Yu, Q. Z., Yang, Y. G., \& Mao, W. H. (2019). Quality of service evaluation on science and technology finance platform based on SERVQUAL model: A case study of P2P lending platform. Science and Technology Management Research, 39(11), 113-121. https://doi.org/10.3969/j.issn.1000-7695.2019.11.016

[28] Wang, Y. \& Feng, L. (2016). Research on operation of scitech finance platform based on multiple cases. Science and Technology Management Research, 36(8), 26-31. https://doi.org/10.3969/j.issn.1000-7695.2016.08.005

[29] Li. C. Y. \& Zhang, Y. (2018). Research on the dynamic mechanism of regional science and technology resource sharing platform development. Information Studies: Theory \& Application, 41(4), 33-37. https://doi.org/10.16353/j.cnki.1000-7490.2018.04.007

[30] Chesbrough, H. \& Crowther, A. K. (2006). Beyond high tech: Early adopters of open innovation in other industries. $R \& D$ Management, 36(3), 229-236. https://doi.org/10.1111/j.1467-9310.2006.00428.x

[31] Eloranta, V. \& Turunen, T. T. (2015). Platforms in servicedriven manufacturing: Leveraging complexity by 
connecting, sharing, and integrating. Industrial Marketing Management, 55, 178-186. https://doi.org/10.1016/j.indmarman.2015.10.003

[32] Yu, H. L., Chen, C. C., \& Lin, N. (2019). Internet+ agricultural science and technology service cloud platform building and agricultural space-time recommendation algorithm. Journal of Jilin Agricultural University, 41(4), 495-504. https://doi.org/10.13327/j.jilau.2019.3769

[33] Yang, Z. H. \& Xiao, Z. Y. (2016) Study on the construction and operation of sci-tech financial service information cooperation platform. Science and Technology Management Research, 34(2), 90-94. https://doi.org/10.19445/..cnki.15-1103/g3.2016.02.023

[34] Cheng, T., Liu Q. J., \& Yang, Y. (2018). Discussion on "Internet+" service mode of Beijing science and technology conditions platform. Science and Technology Management Research, 38(14), 224-229. https://doi.org/10.3969/j.issn.1000-7695.2018.14.034

[35] Zhang, Q., Cao, M., Zhang, F., Liu, J., \& Li, X. (2019). Effects of corporate social responsibility on customer satisfaction and organizational attractiveness: A signaling perspective. Business Ethics: A European Review, 29(3), 2034. https://doi.org/10.1111/beer.12243

[36] Qian, H. (2019). Research on the science and technology intelligence service platform for technological innovation ecosystem. China Science \& Technology Resources Review, 51(5), 83-88. https://doi.org/10.3772/j.issn.1674-1544.2019.05.013

[37] Fan, Y. X., Jiang, J. M., \& Liu, C. (2019). Ecosystem for Chinese scientific journals serving technological innovation. Acta Editologica, 31(2), 134-137. https://doi.org/10.16811/j.cnki.1001-4314.2019.02.004

[38] Jacobides, M. G. (2008). How capability differences, transaction costs, and learning curves interact to shape vertical scope. Organization Science, 19(2), 306-326. https://doi.org/10.1287/orsc.1070.0312

[39] Inoue, Y. \& Tsujimoto, M. (2017). New market development of platform ecosystems: A case study of the Nintendo Wii. Technological Forecasting \& Social Change, 136, 235-253. https://doi.org/ 10.1016/j.techfore.2017.01.017

[40] Moore, J. F. (1993). Predators and prey: A new ecology of competition. Harvard Business Review, 71(3), 75-83. https://doi.org/10.1111/j.1744-1714.1993.tb00677.x

[41] Pan, X., Chen, X., Guo, H., \& Zhang, Y. (2020). One size doesn't fit all: how institutional complexity within the state shapes firms' environmental innovation. Business Ethics: A European Review. Retrieved from https://onlinelibrary.wiley.com/doi/abs/10.1111/beer.12280. https://doi.org/10.1111/beer.12280

[42] Li, K., An, S., \& Wang C. L. (2018). Competition mechanism of enterprises' knowledge transmission based on Lotka-Volterra ecological model. R\&D Management, 30(3), 75-84. https://doi.org/10.13581/j.cnki.rdm.2018.03.008

[43] Wei, T., Zhu, Z., Li, Y., \& Yao, N. (2018). The evolution of competition in innovation resource: a theoretical study based on Lotka-Volterra model. Technology Analysis \& Strategic Management, 30(3), 295-310. https://doi.org/10.1080/09537325.2017.1309014

[44] Moore, J. F. (2006). Business ecosystems and the view from the firm. Antitrust Bulletin, 51(1), 31-75. https://doi.org/10.1177/0003603X0605100103

[45] Fan, D. C. \& Li, S. N. (2018). Research on technological innovation efficiency of high-tech industry considering spatial effects. Studies in Science of Science, 36(5), 901-912. https://doi.org/10.16192/j.cnki.1003-2053.2018.05.015

[46] Néstor, D. B., de Panizza Andrea, \& Kholilul, R. I. (2018). Innovation and productivity in a science-and-technology intensive sector: Information industries in Spain. Science \& Public Policy, 45. https://doi.org/10.1093/scipol/scx072
[47] Guerrieri, P. \& Meliciani, V. (2005). Technology and international competitiveness: The interdependence between manufacturing and producer services. Structural Change and Economic Dynamics, 16(4), 489-502. https://doi.org/10.1016/j.strueco.2005.02.002

[48] Muller, E. \& Zenker, A. (2001). Business services as actors of knowledge transformation: The role of KIBS in regional and national innovation systems. Research Policy, 30, 15011516. https://doi.org/10.1016/S0048-7333(01)00164-0

\section{Contact information}

Jingdong YAN, PhD, Professor

School of Management, Wuhan University of Technology, No. 122, Luoshi St. Wuhan, 430070, P. R. China

E-mail: yjdong02@163.com

Xiao YU, PhD Candidate

(Corresponding author)

School of Management, Wuhan University of Technology, No. 122, Luoshi St. Wuhan, 430070, P. R. China

E-mail: yuxia014@foxmail.com

Pincheng LIU, PhD Candidate

School of Management, Wuhan University of Technology, No. 122, Luoshi St. Wuhan, 430070, P. R. China

E-mail: 15002707485@163.com

Quan ZHANG, PhD Candidate

School of Management, Wuhan University of Technology, No. 122, Luoshi St. Wuhan, 430070, P. R. China

E-mail: Zhangquanwhut@163.com 